\title{
Outcome Analysis of Locking Plate Fixation in Proximal Humerus Fractures
}

\author{
Thirunarayanan $\mathrm{V}^{1}$, Ramprasath $\mathrm{D} \mathrm{R}^{2}$, Amarnath $\mathrm{R}^{3}$, Basheer Ahmed $\mathrm{S}^{4}$ \\ ${ }^{1}$ Associate Professor, Dept. of Orthopaedic Surgery, Govt. Dharmapuri Medical College Hospital. \\ ${ }^{2}$ Associate Professor, Dept. of Orthopaedic Surgery, Govt Coimbatore Medical college Hospital. \\ ${ }^{3}$ Senior Assistant Professor, Dept. of Orthopaedic Surgery, Govt. Royapettah Hospital ,Chennai-14. \\ ${ }^{4}$ Resident, Dept. of Orthopaedic surgery, Govt. Royapettah Hospital, Chennai-14.
}

\begin{abstract}
Overall incidence of Proximal humerus fracture is about 5-6\% which contributes to $45 \%$ of total humerus fractures. Though undisplaced fractures can be managed conservatively, nearly $51 \%$ of these fractures are displaced and need surgical treatment for early return to daily activities. Various surgical options are available. Our study is a prospective study including 41 patients with proximal humerus fractures. Fractures were classified using Neer's classification as 2, 3 and 4 parts and locking plates ( Proximal Humerus Internal Locking System (PHILOS) \& Locking Proximal Humerus Plate (LPHP)) were used for fracture fixation using Deltopectoral approach. Functional outcome was analysed using Constant score at 3, 6 \&9 months. Functional outcome was analysed based on age, fracture pattern and implant type \& the results compared with similar other studies. Statistical analysis was performed using Microsoft Excel 2010 \& IBM SPSS software by statistical consultant and student $t$ test. We found young patients and less comminuted fractures showed better results. Also PHILOS plate showed a slight advantage over LPHP which may be due to the implant design.
\end{abstract}

Keywords: Proximal humerus fractures, Constant score, Neer classification, PHILOS, LPHP.

\section{Introduction}

Overall incidence of proximal humerus fractures is about 5-6\% [1] and they are most common of the fractures of humerus(45\%) [2]. Majority of these fractures occur in elderly patients of age more than 65 years [3] after sustaining low velocity injury like slip and fall and the reason may be due to osteoporosis whereas in younger patients these fractures are produced by high velocity injuries and are usually associated with dislocation [4]. While undisplaced fractures can be managed conservatively [5] with U-slab, more than half (51 $\%$ ) of these fractures are displaced and majority (77\%) involves the surgical neck of humerus [6]. In elderly, fixation of these fractures look initially stable but late complications like loss of reduction, screw pull out and varus collapse may occur due to osteoporotic quality of bone [7].

The aim of treatment is to achieve fracture union and good range of movements in painless shoulder. Various treatment options are available and they includes percutaneous or open $\mathrm{K}$ wire fixation, tension band wiring, transosseous suture fixation, locking proximal humerus plates, intramedullary interlocking nails, prosthesis replacements and recently variable angle locking plates. Every technique has its own advantages and complications. PHILOS provides more stable fixation in osteoporotic bones as it provides more angular stability and locking screws results in lower complication rates and these are now widely used for fixation of proximal humerus fractures $[8,9]$. The aim of our study is to analyse the functional outcome and radiological union of proximal humerus fractures treated with locking Plates and to do comparative analysis between PHILOS and LPHP.

\section{Materials \& Methods}

Our study is a prospective study involving 41 patients admitted in Government Royapettah Hospital, Chennai during May 2011 to July 2016 with proximal humerus fractures of age group 20 to 67. Patient demographics \& fracture charachteristics are shown in table 1. Fractures were classified using Neer classification of proximal humerus. All patients admitted with closed fractures of proximal humerus( 2 part, 3 part, 4 part according to Neer) less than 3 weeks old without neurological \& vascular injury are included in the study. Open fractures, pathological fractures, refractures, fractures more than 3 weeks old, fractures with short calcar less than $8 \mathrm{~mm}$, disrupted medial hinge more than $2 \mathrm{~mm} \&$ anatomic neck fractures are excluded.

The patients are initially resuscitated and stabilised in the emergency department and obtained informed written consent for study and surgical procedure. All patients were operated by experienced Orthopaedic team in supine position with sandbag under interscapular region under general anesthesia or regional block. We followed standard Deltopectoral approach with minimal soft tissue dissection for all patients. The fracture reduced and provisionally held with $\mathrm{K}$ wires , checked under $\mathrm{C}$-arm and then either the PHILOS 
plate or LPHP was used to fix the fracture. The wound was closed with a suction drain. The datas like duration of surgey, blood loss during the surgery, any intraoperative complications were recorded for analysis.

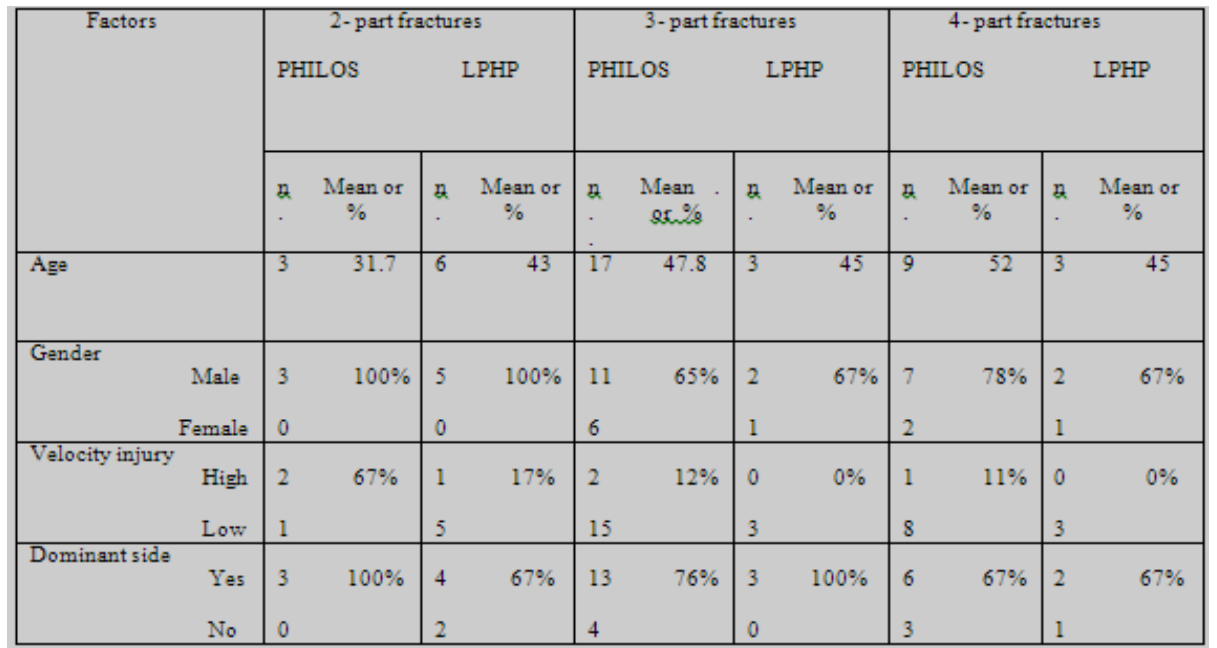

Table1: Patient demographics \& fracture charachteristics

\section{Post operative protocol}

Post operatively drain removed on $2^{\text {nd }}$ day, passive mobilization exercise and pendulum exercises started on $3^{\text {rd }}$ day, suture removal done on $12^{\text {th }}$ day. Gradually mobilization increased on the basis of patient's pain tolerance.

AP and Lateral radiographs were taken at 4 weeks interval upto 20 weeks and then at, $6^{\text {th }}$ and $9^{\text {th }}$ month and radiological union were observed on the basis of bridging osseous trabeculae and cortical continuity. Presence of complications like loss of reduction, screw pull out, refracture were also analysed. Functional outcome was assessed using Constant- Murley score at $3^{\text {rd }}, 6^{\text {th }}$ and $9^{\text {th }}$ month which includes pain, activity level, arm position, strength of abduction and patients were categorized as excellent (86-90), good (71-85), moderate (56-70), and poor (0-55).[10]

\section{Case Illustration}

IV.1. Case 1. 80 years female patient admitted with history of trivial fall at home and sustained Neer 4 part proximal humerus fracture (Fig.1).Fracture treated with PHILOS plate (Fig.2). 5 years follow up of the patient showed good functional outcome( Fig.3)

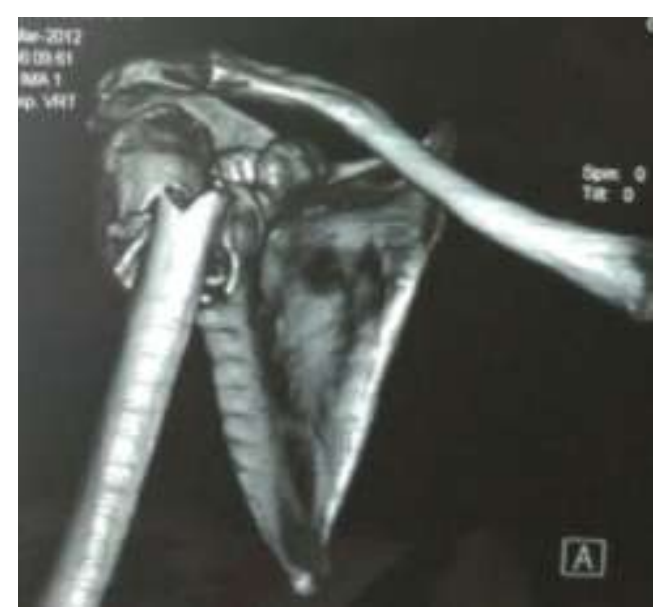

Fig.1.CT showing Neer 4 part proximal humerus fracture

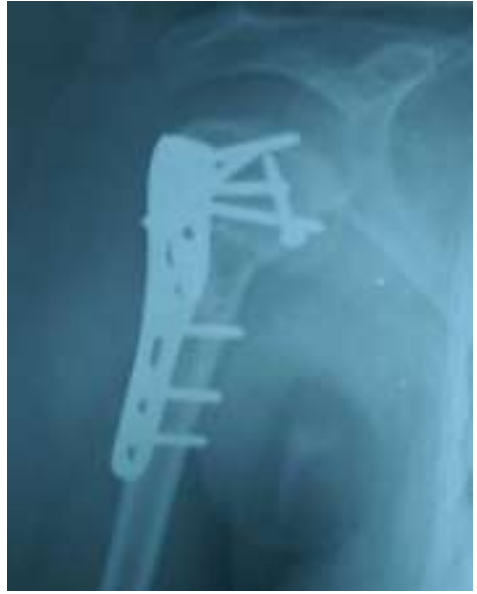

Fig.2. 5 years post op x ray . showing good fracture union 


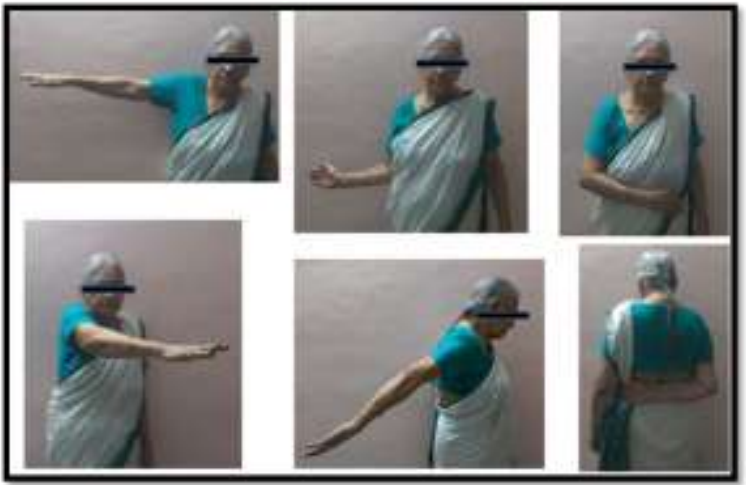

Fig.3. 5 years follow up of the patient with good functional outcome

IV.2.Case 2. 65 years male patient admitted with history of slip \& fall at home and sustained Neer 3 part proximal humerus fracture (Fig.4).Fracture treated with PHILOS plate (Fig.5). $2 \frac{1}{2} 2$ years follow up of the patient showed excellent functional outcome( Fig.6)

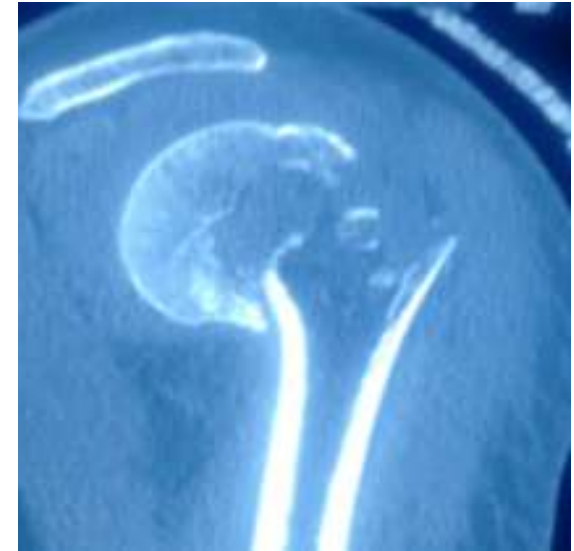

Fig.4.CT showing Neer 3 part humerus fracture

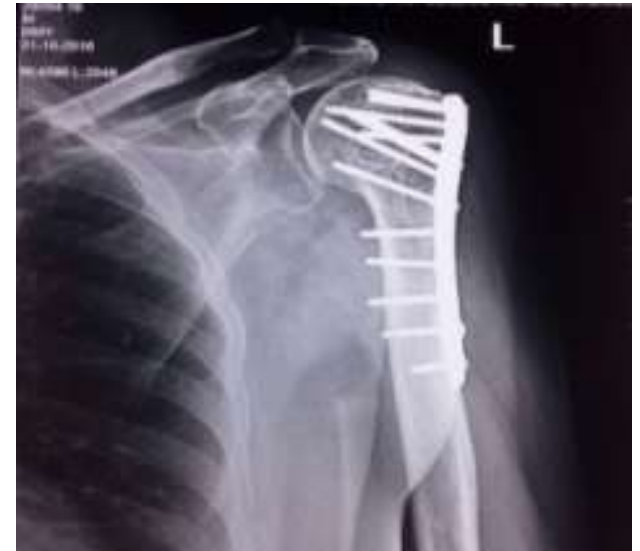

Fig.5. $2 \frac{1}{1} 2$ years post op $\mathrm{x}$ ray showing proximal good fracture union

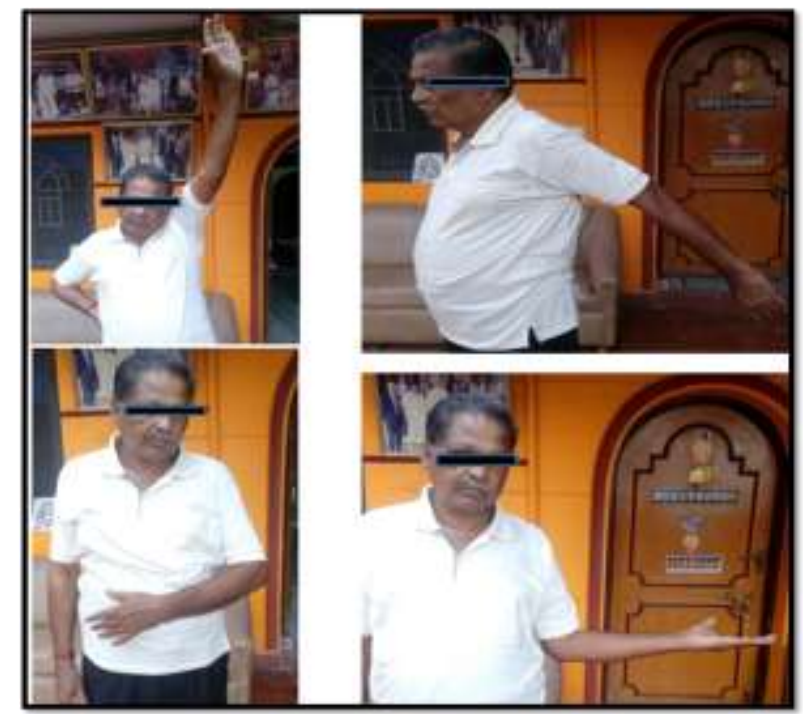

Fig.6. $2 \frac{1}{2}$ years follow up of the patient with excellent functional outcome

IV.3.Case 3. 36 years male patient admitted with history of self fall and sustained Neer 2 part proximal humerus fracture left side (Fig.7). Fracture treated with PHILOS plate showing good union (Fig.8). 1 year follow up of the patient with excellent functional outcome ( Fig.9) 


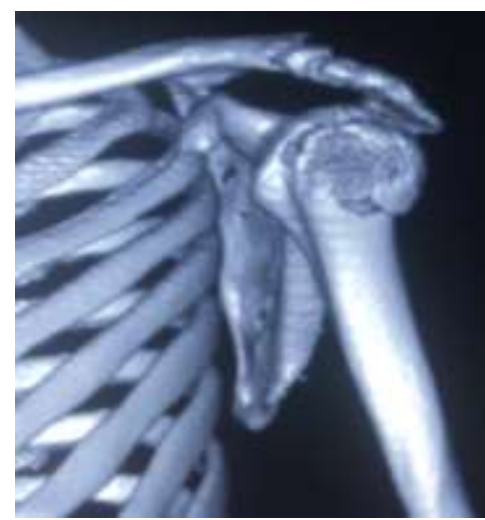

Fig.7. Neer 2 part proximal humerus fracture

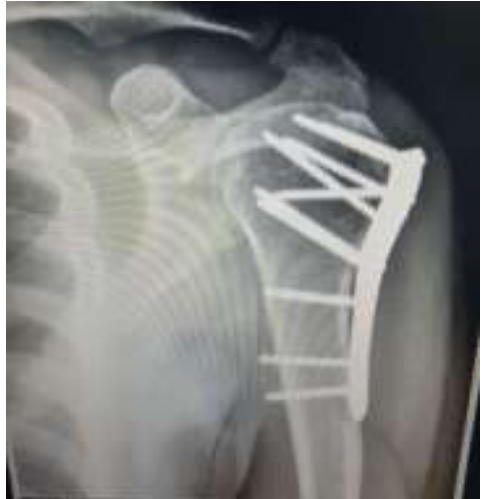

Fig.8. 1 year post op x ray showing PHILOS with good union
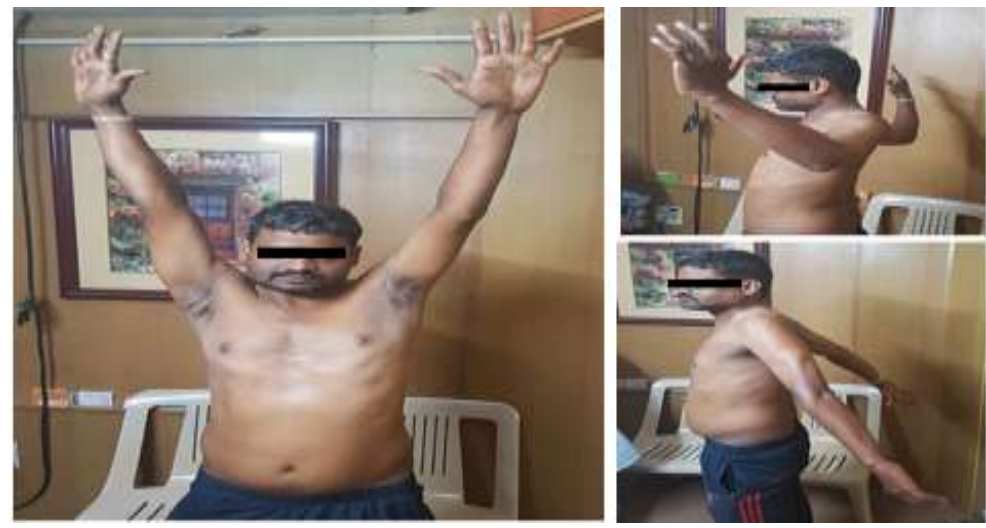

Fig.9. 1 year follow up with excellent functional outcome

\section{Statistical Analysis}

Statistical analysis was performed using Microsoft Excel 2010 \& IBM SPSS software by statistical consultant. Categorical variables were tabulated with absolute and relative frequencies. The null hypothesis that there would be no difference between PHILOS and LPHP was tested with student $t$ test and level of significance being 0.05

\section{Results}

All 41 patients in our study achieved union both clinically and radiologically with mean time of 12.4 weeks( $9-16$ weeks). The mean age of the patients was 46.58 years with minimum age of 23 years and maximum of 67 years. The male:female ratio was 2.7:1 with male predominance. Dominant side was involved more commonly with the ratio being 3.1:1 which was due to right handedness of the majority of the population. The most common mode of injury was due to fall (78\%) followed by road traffic accident (22\%). We operated all the patients within 7 days of onset of injury. The majority of fractures in our study were Neer's type 3 part $(48.8 \%)$, followed by 4 part $(29.3 \%)$ and remaining from 2 part $(21.9 \%)$ fractures (Table 2$)$.

Mean constant score at final follow-up at the end of 9 months was 71.12 with 3 patients (7\%) had excellent outcome and all the three belongs to 2 part type out of which PHILOS were used in 2 patients and LPHP in 1 patient, 23 patients (56\% of total patients that includes six 2-part, thirteen 3 part and four 4-part fractures ) had good score , 12 patients (29\% of total patients that includes six 3-part and six 4-part fractures) had moderate score, and 3 patients (7\% of total that includes one 3-part and two 4-part fractures ) had poor outcome.(Fig.10) 


\begin{tabular}{|c|c|c|c|}
\hline $\begin{array}{c}\text { Neer } \\
\text { Classification }\end{array}$ & $\begin{array}{c}\text { Total No. } \\
\text { of Cases (n) }\end{array}$ & $\begin{array}{c}\text { Treated by } \\
\text { PHILOS plate }\end{array}$ & $\begin{array}{c}\text { Treated by } \\
\text { LPHP plate }\end{array}$ \\
\hline 2-part & 9 & 3 & 6 \\
\hline 3-part & 20 & 17 & 3 \\
\hline 4-part & 12 & 9 & 3 \\
\hline Total & 41 & 29 & 12 \\
\hline
\end{tabular}

Table 2: No. of cases as per Neer classification and implant used.

\begin{tabular}{|c|c|c|}
\hline Age of patient & $\begin{array}{c}\text { Total no. of } \\
\text { patients (n) }\end{array}$ & $\begin{array}{c}\text { Mean Constant score at 9 } \\
\text { months }\end{array}$ \\
\hline $\mathbf{2 0 - 3 0}$ & 6 & 78.25 \\
\hline $\mathbf{3 0 - 4 0}$ & 8 & 74 \\
\hline $\mathbf{4 0 - 5 0}$ & 6 & 70.3 \\
\hline $\mathbf{5 0 - 6 0}$ & 14 & 68.5 \\
\hline $\mathbf{6 0 - 7 0}$ & 7 & 67.4 \\
\hline
\end{tabular}

Table3: Evaluation on basis of age group of patients and average of Constant Murley shoulder score.

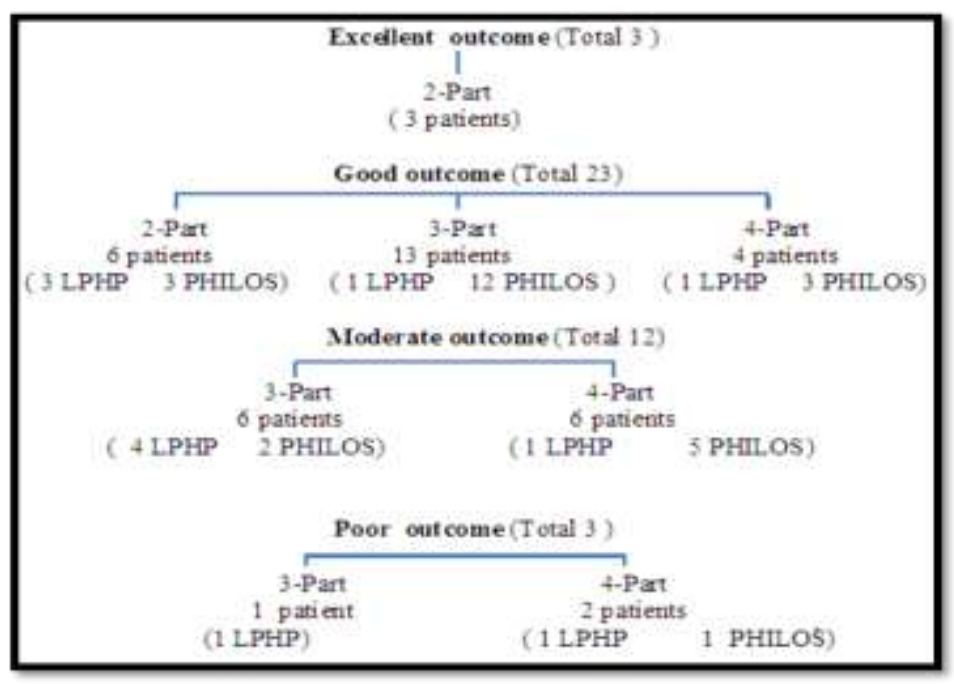

Fig. 10: Functional outcome

VII. Discussion

Our study population comprises mostly of young and middle aged people with low velocity injury. Whereas the age group in the study by Faraj et al. [11] , Neer et al. [12] , Frankhauser et al. [13] , comprises of elderly population who sustained fracture following trivial trauma. There was $100 \%$ follow up. The overall results we obtained were good to excellent based on the constant score.

For 2 part fracture constant score is better at 3,6, and 9 months when compared to the 3 and 4 part fractures (Fig.11). In a SICOT 2012 International orthopaedic multicentric trial by G Konrad et al.[14] which is based on comparison of two different locking plates for proximal humerus fractures, their population also showed good functional outcome for 2-part fractures with PHILOS plate when compared to 3 and 4 part fractures. The reasons they quoted in their study is shorter surgical time and minimal soft tissue injury for 2 part fracture with PHILOS plate, which in turn have good healing with reduced postoperative pain resulting in early rehabilitation and good functional outcome. Also prospective studies by Mayank et al. [15] in indian population and Bjorkenheim et al. [16 ] in finnish population obtained better outcome in patients with 2-part fractures compared to the 3 and 4 part fractures based on constant scores using PHILOS plate. In a retrospective study by Faraj et al. [11] involving 131 patients with more than two year follow up in netherland population conducted through telephonic interviews based on Visual analogue scale and Oxford shoulder score also showed similar results.

Whereas there is no significant difference in the functional outcome between 3 and 4 part fractures at 9 months which is also observed by Mayank et al. [15] and Faraj et al. [11]in their studies. But in a retrospective review of prospective collected data in 22 patients from Pakistan population using DASH score by A.M.Aliuddin et al. [17] they found that there was no difference in outcome based on increasing comminution. 


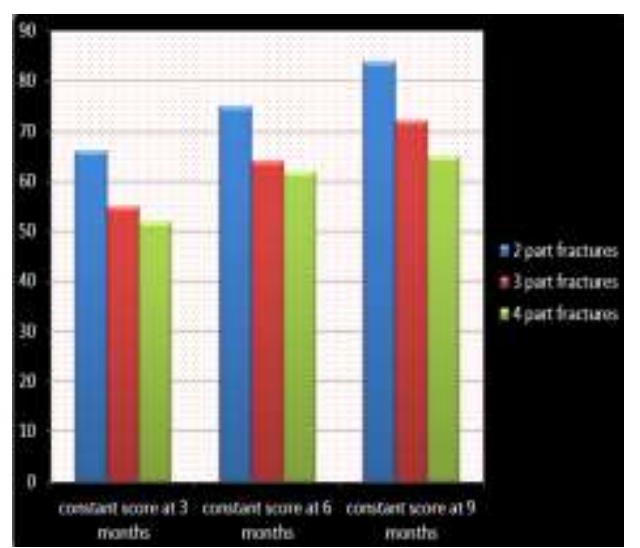

Fig.11.Evaluation on basis of neer fracture type \& Constant score

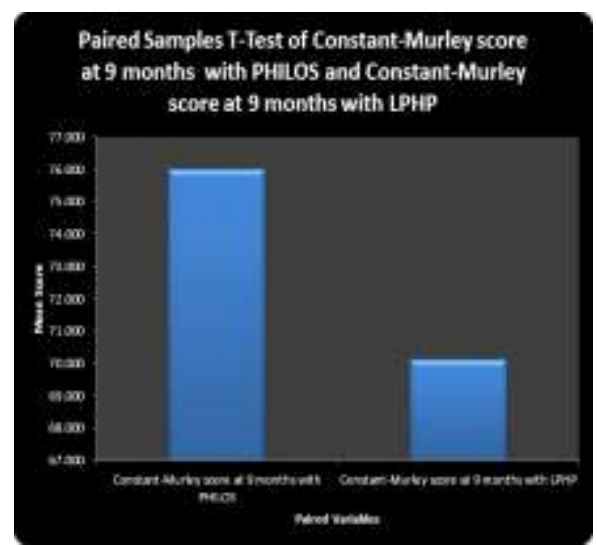

Fig.12.Paired samples t test of constant score at 9 months between PHILOS \& LPHP.

Though our groups are asymmetrical with large number of patients in PHILOS ( $\mathrm{n}=29$ ) than $\operatorname{LPHP}(n=12)$, we used paired samples t test to evaluate the overall (i.e. for all 2-part,3-part,4-part) difference in functional outcome between two groups at 3,6 and 9 months. There is no significant difference in the functional outcome of patients at 3 and 6 months but at 9th month, the mean constant score of patients treated with PHILOS (76.0) is slightly higher than that with LPHP ( 70.1) which is statistically significant (Fig.12) with a pvalue of 0.023 in paired samples t test (Fig.12).This statistical significant functional outcome for proximal humerus fractures treated with PHILOS plate irrespective of its comminution is different from the SICOT 2012 International orthopaedic multicentric trial by $G$ Konrad et al.[14] in which PHILOS gave statistically significant better outcome only in 2-part fractures. We would like to quote the reason postulated by G Konrad et al. for their statistically significant better outcome with PHILOS plate for the 2-part fractures as "implant design (i.e.) the proximal part of the PHILOS plate is slightly larger and longer than that of LPHP with additional angular stable and oblique screws which aids in better fixation of head fragment. [14] The length also aids in indirect reduction maneuver".

In our study population, 7\% ( 3/41) were diagnosed with Subacromial impingement (SAI) which is found to be a major complication. Siwach et.al. [18] reported a similar rate of $8 \%$ in their study. The systematic review of 12 studies on proximal humerus fractures by Thanasas et al. [9] reported the impingement rate of $5.5 \%$. Stiffness was reported in 7\% (3/41). All these patients were above 65 years, associated with diabetes and found to have not followed the standard physiotherapy exercises in the postoperative period. One patient had chronic pain $(2 \%)$ which subsided on analgesics but recurred with activity. The patient is in follow up and may be advised for implant removal if pain persists. Of all, only one patient (2\%)had superficial infection that was treated with sensitive intravenous antibiotic. Infection rate of $2 \%$ was reported Brunner et al. [19] and $4.5 \%$ was reported by Agudelo et al. [20] in their studies. One patient with 2 part fracture treated by LPHP had a varus malunion (2\%) since patient was able to do her daily activities with moderate functional outcome, revision was not performed.

In our study mean final constant score is 71.12 with a complication rate of $20 \%$ which was similar to other studies of proximal humerus fracture fixation by Moonet et al. ( 32 patients with mean final constant score of 66.5 with complication rate 22\%) [8], Bjorkenheim et al. (72 patients with mean final constant score of 72 with complication rate 9\%) [16], koukakis et al. (20 patients with mean final constant score of 76.1with complication rate 10\%) [21], Hente et al. (31 patients with mean final constant score of 76 with complication rate $31 \%$ ) [22], Mayank et al. ( 26 patients with mean final constant score of 72.5 with complication rate $15 \%$ ) [15].No complication of avascular necrosis or plate breakage occurred in our study.

Eventhough many studies support surgical intervention for displaced proximal humerus fractues, A pragmatic, multicenter, parallel-group, randomized clinical trial, the Proximal Fracture of the Humerus Evaluation by Randomization (PROFHER) Trial, which is a recent landmark article on management of proximal humerus fractures by Amar Rangan et al. [23] involving 250 patients with 2years follow up concluded that among patients with displaced proximal humeral fractures involving the surgical neck, there was no significant difference between surgical treatment compared with nonsurgical treatment in patient-reported clinical outcomes over 2 years following fracture occurrence. So they are strictly against the increasing trends of surgeries for all proximal humerus fractures. But we feel surgery provides early mobilization of the patient which is necessary for the patient to get back to his regular activities which is also necessary for psychological improvement in elderly patients. 


\section{Limitations}

The number of patients in our study is less $(n=41)$ and also only one patient with longest follow up of 5 years and so we are not able to assess the late complications of these fracture fixations. Also two groups with 29 patients in PHILOS group and 12 patients in LPHP group is asymmetrical .These are three major limitations in our study. So we suggest larger sample size, longer follow up for all patients in the study and comparable groups for further validation of results.

\section{Conclusion}

To conclude, both PHILOS plate and LPHP can be considered as good implant for fixation of proximal humerus fractures but PHILOS have slight advantage over LPHP which may be due to the implant design. Also principles of fixation should be strictly followed in articular fractures to restore the articular congruity.

\section{References}

[1]. Court-Brown CM, Caesar B. Epidemiology of adult fractures: a review. Injury. 2006;37(8):691-697.

[2]. Helmy N, Hintermann B. New trends in the treatment of proximal humerus [1]fractures. Clin Orthop. 2006;442:100-08.

[3]. Kim SH, Szabo RM, Marder RA. Epidemiology of humerus fractures in the United States: nationwide emergency department sample, 2008. Arthritis Care Res (Hoboken). 2012;64(3):407-414.

[4]. Flatow EL. Fractures of the proximal humerus. Rockwood and Green's fractures in adults. Fifth edition. Philadelphia: Lippincott Williams \& Wilkins. 2001:997-1040

[5]. Young TB, Wallace WA. Conservative treatment of fractures and fracture-dislocations of the upper end of the humerus. Bone \& Joint Journal. 1985 May 1;67(3):373-7.

[6]. Court-Brown CM, Garg A,McQueen MM. The epidemiology of proximal humeral fractures. Acta Orthop Scand. 2001;72(4):365371.

[7]. Kannus P, Palvanen M, Niemi S, et al. Osteoporotic fractures of the proximal [3]humerus in elderly Finnish persons: sharp increase in 1970-1998 and alarming projections for the new millennium. Acta Orthop Scand. 2000;71:465-70.

[8]. Moonot P, Ashwood N, Hamlet M. Early results for treatment of three- and four-part fractures of the proximal humerus using the PHILOS plate system. J Bone Joint Surg Br. 2007;89(9):1206-09

[9]. Thanasas C, Kontakis G, Angoules A, Limb D, Giannoudis P. Treatment of proximal humerus fractures with locking plates: a systematic review [published online ahead of print September 12, 2009]. J Shoulder Elbow Surg. 2009;18(6):837-44

[10]. Constant CR, Murley AG. A clinical method of functional assessment of the shoulder. Clin Orthop 1987 Jan 1;214:160-4.

[11]. Faraj D, Kooistra BW, Vd Stappen WA, Werre AJ. Results of 131 consecutive operated patients with a displaced proximal humerus fracture: an analysis with more than two years follow-up. Eur J Orthop Surg Traumatol. 2011 Jan 1;21(1):7-12.

[12]. Neer CS. Displaced proximal humeral fractures. J Bone Joint Surg Am. 1970 Sep 1;52(6):1090-103.

[13]. Fankhauser F, Boldin C, Schippinger G, Haunschmid C, Szyszkowitz R. A new locking plate for unstable fractures of the proximal humerus. Clin Orthop. 2005 Jan 1;430:176-81.

[14]. Konrad G, Hirschmüller A, Audige L, Lambert S, Hertel R, Südkamp NP. Comparison of two different locking plates for two-, three-and four-part proximal humeral fractures — results of an international multicentre study. Inter Orthop. 2012 May 1;36(5):10518

[15]. Vijayvargiya M, Pathak A, Gaur S. Outcome Analysis of Locking Plate Fixation in Proximal Humerus Fracture. J Clin Diagn Res:. 2016 Aug; 10(8):RC01.

[16]. Björkenheim JM, Pajarinen J, Savolainen V. Internal fixation of proximal humeral fractures with a locking compression plate A retrospective evaluation of 72 patients followed for a minimum of 1 year. Acta orthopaedica Scandinavica. 2004 Jan 1;75(6):741-5

[17]. Aliuddin AM, Idrees Z, Zamir M, Najjad MK, Shah SA. FUNCTIONAL OUTCOME OF PROXIMAL HUMERAL FRACTURES TREATED WITH PHILOS PLATE IN ADULTS. J Ayub Med Coll Abbottabad. 2016 Jun 1;28(2).

[18]. Siwach R, Singh R, Rohilla RK, Kadian VS, Sangwan SS, Dhanda M. Internal fixation of proximal humeral fractures with locking proximal humeral plate (LPHP) in elderly patients with osteoporosis. J Orthop Traumatol. 2008 Sep 1;9(3):149-53

[19]. Brunner F, Sommer C, Bahrs C, Heuwinkel R, Hafner C, Rillmann P, Kohut G, Ekelund A, Muller M, Audigé L, Babst R. Open reduction and internal fixation of proximal humerus fractures using a proximal humeral locked plate: a prospective multicenter analysis. J Orthop trauma. 2009 Mar 1;23(3):163-72.

[20]. Agudelo J, Schürmann M, Stahel P, Helwig P, Morgan SJ, Zechel W, Bahrs C, Parekh A, Ziran B, Williams A, Smith W. Analysis of efficacy and failure in proximal humerus fractures treated with locking plates. J Orthop trauma. 2007 Nov 1;21(10):676-81.

[21]. Koukakis A, Apostolou CD, Taneja T, Korres DS, Amini A. Fixation of proximal humerus fractures using the PHILOS plate: early experience. Clin Orthop. 2006 Jan 1;442:115-20.

[22]. Hente R, Kampshoff J, Kinner B, Füchtmeier B, Nerlich M. [Treatment of dislocated 3-and 4-part fractures of the proximal humerus with an angle-stabilizing fixation plate]. Der Unfallchirurg. 2004 Sep;107(9):769-82.

[23]. Rangan A, Handoll H, Brealey S, Jefferson L, Keding A, Martin BC, Goodchild L, Chuang LH, Hewitt C, Torgerson D. Surgical vs nonsurgical treatment of adults with displaced fractures of the proximal humerus: the PROFHER randomized clinical trial. JAMA. 2015 Mar 10;313(10):1037-47. 